\title{
A Novel Button-Type Micro Direct Methanol Fuel Cell with Graphene Diffusion Layer
}

\author{
Yingli Zhu *(D), Lei Gao and Jianyu Li \\ Tianjin Key Laboratory of Integrated Design and On-line Monitoring for Light Industry \& Food Machinery and \\ Equipment, School of Mechanical Engineering, Tianjin University of Science \& Technology, Tianjin 300384, \\ China; 18853561233@163.com (L.G.); lijianyu@tust.edu.cn (J.L.) \\ * Correspondence: zhuyingli@tust.edu.cn; Tel.: +86-1822-288-8690
}

Received: 28 August 2019; Accepted: 27 September 2019; Published: 29 September 2019

\begin{abstract}
In order to solve the problem that bolts in traditional packaged direct methanol fuel cells (DMFCs) take up a large area and reduce the specific energy (energy per unit weight) and power density (power per unit area), a new button-type micro direct methanol fuel cell (B- $\mu D M F C$ ) is designed, assembled, and packaged. The cell with four different structures was tested before and after packaging. The results indicate that the button cell with three-dimensional graphene and springs has the best performance. The equivalent circuit and methanol diffusion model was applied to explain the experimental results. The peak volumetric specific power density of the cell is $11.85 \mathrm{~mW} \mathrm{~cm}$. This is much higher than traditional packaged DMFC, because the novel B- $\mu$ DMFC eliminates bolts in the structure and improves the effective area ratio of the cell.
\end{abstract}

Keywords: micro direct methanol fuel cells ( $\mu \mathrm{DMFCs})$; button-type; graphene; gas diffusion layer (GDL)

\section{Introduction}

Close attention [1-3] has been paid to the micro direct methanol fuel cell ( $\mu$ DMFC), because it is the potential mobile energy for portable devices [4-7]. The packaging technology of $\mu$ DMFC affects the internal resistance of the cell and the specific energy of the cell, thereby affecting the overall output performance of the cell. It is necessary to ensure the components are in good contact and have high porosity of the diffusion layer. Most packaging methods are mechanical bonding, hot pressing, and high polymer bonding. Takahiro Shimizu [8] reported a self-breathing direct methanol fuel cell packaged by bolting plexiglass. Kyong-Bok Min [9], J. Yeom [10], and Guo Zhen [11] encapsulated fuel cells by thermo-compression bonding, but the output performance of the cell was relatively poor. It is difficult to form a strong bonding layer in the interface and reduce the contact resistance with the method of thermo-compression bonding. Thus, it limits the output performance of the cell. Therefore, the packaging of traditional block-type fuel cells usually requires a lot of bolts for moderate compression pressure to obtain lower ohmic resistance and mass transfer resistance. The existence of bolts, however, may consume a large volume of the cell and reduce the power density per unit volume, especially for micro cells.

In order to solve this problem, a new button-type micro direct methanol fuel cell (B- $\mu$ DMFC) is designed, assembled, and packaged. The design of the B- $\mu$ DMFC is based on the layout of the traditional block-type direct methanol fuel cell and that of the button-type zinc-air batteries [12]. In addition, this paper especially compares the performances of B- $\mu$ DMFCs with different material structures and analyzes the mechanism using the equivalent circuit and diffusion model. 


\section{Experimental}

The proton exchange membrane (PEM) of the B- $\mu$ DMFCs was DuPont's Nafion 117 membrane, with a thickness of $183 \mu \mathrm{m}$. The catalyst layer was applied on both sides of the Nafion 117 membrane. The anode catalyst loading was $4 \mathrm{mg} \cdot \mathrm{cm}^{-2}$ carbon-supported $1: 1 \mathrm{Pt} / \mathrm{Ru}$, and the cathode side was $2 \mathrm{mg} \cdot \mathrm{cm}^{-2}$ carbon-supported Pt. The PEM diameter was $1.94 \mathrm{~cm}$, as shown in Figure 1. The sealing silica gel gaskets with a thickness of $0.2 \mathrm{~mm}$ are regarded as insulators. Two materials were applied as the gas diffusion layer (GDL) of the cell in this paper. One was three-dimensional graphene (3DG) based on foam nickel(FN) [13] (Shenzhen Six Carbon Technology Co., Ltd., Shenzhen, China) and the other was TGP-090 carbon paper (CP) (Toray Co., Ltd., Tokyo, Japan). The diameter of the titanium-plated stainless steel mesh was $15 \mathrm{~mm}$. Two types of supporting conductive structure (FN and stainless steel springs) were used as current collectors (CCs) in the B- $\mu$ DMFC.
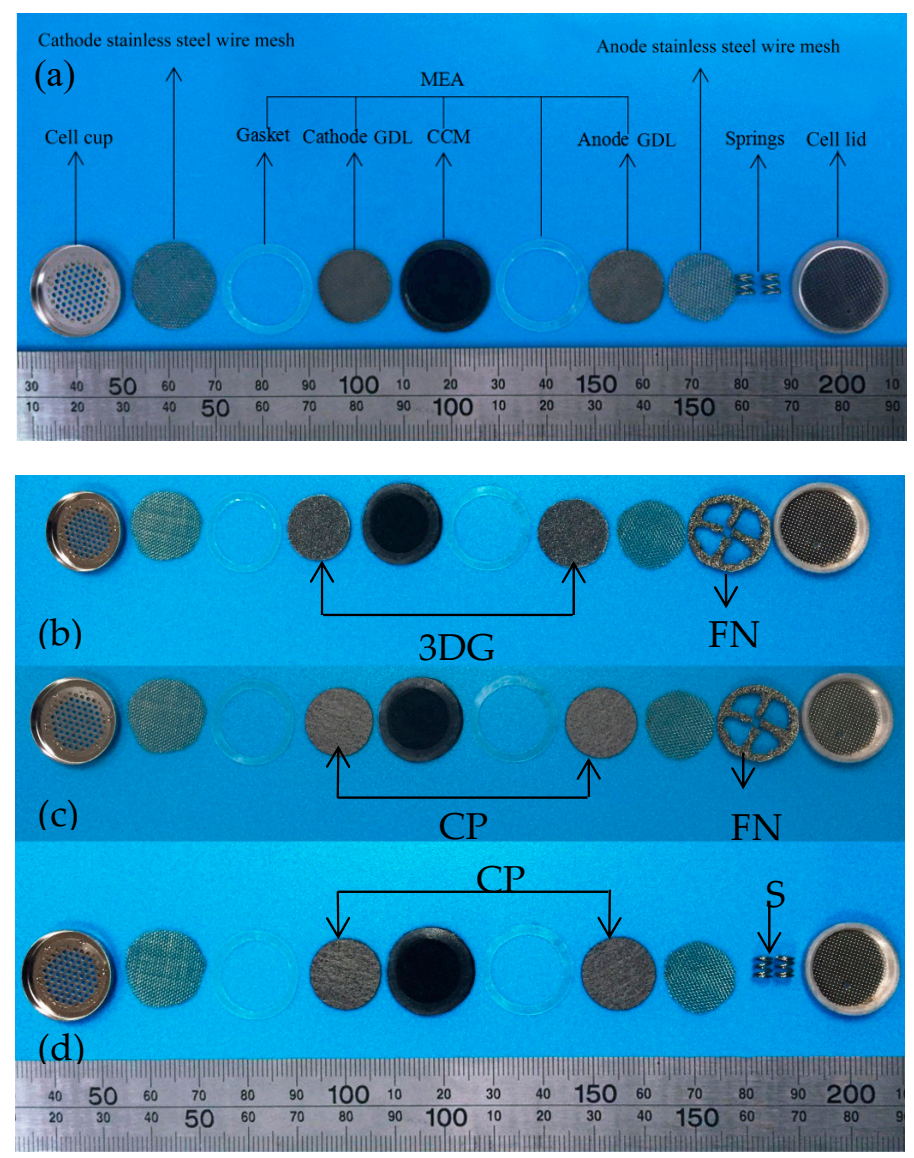

Figure 1. Photograph of the button-type micro direct methanol fuel cell(B- $\mu$ DMFC) components: (a) the three-dimensional graphene-springs (3DG + S) B- $\mu \mathrm{DMFC}$; (b) the 3D graphene-foam nickel $(3 \mathrm{DG}+\mathrm{FN}) \mathrm{B}-\mu \mathrm{DMFC}$; (c) the carbon paper-foam nickel(CP + FN) B- $\mu \mathrm{DMFC}$; and (d) the carbon paper-springs $(\mathrm{CP}+\mathrm{S}) \mathrm{B}-\mu \mathrm{DMFC}$. MEA, membrane electrode assembly; GDL, gas diffusion layer.

The components and structure of the button-type micro direct methanol fuel cell (B- $\mu$ DMFC) are shown in Figures 1 and 2, respectively. Similar to the conventional DMFC, the key component of the cell is a membrane electrode assembly (MEA), which comprised a proton exchange membrane, cathode and anode catalytic layer, and cathode and anode gas diffusion layer. The diameter of the active area of the MEA was $1.5 \mathrm{~cm}$, and thus the area was $1.77 \mathrm{~cm}^{2}$. Carbon paper and three-dimensional graphene were adopted as the cathode and anode GDL, respectively. In order to reduce the internal contact resistance of the cell and support the GDL, a titanium-plated stainless steel wire mesh was added 
between the gas diffusion layer and the end plate on both sides of the anode and cathode. The lid and cup of standard lithium battery were used as the anode and the cathode end plate of the B- $\mu \mathrm{DMFC}$.

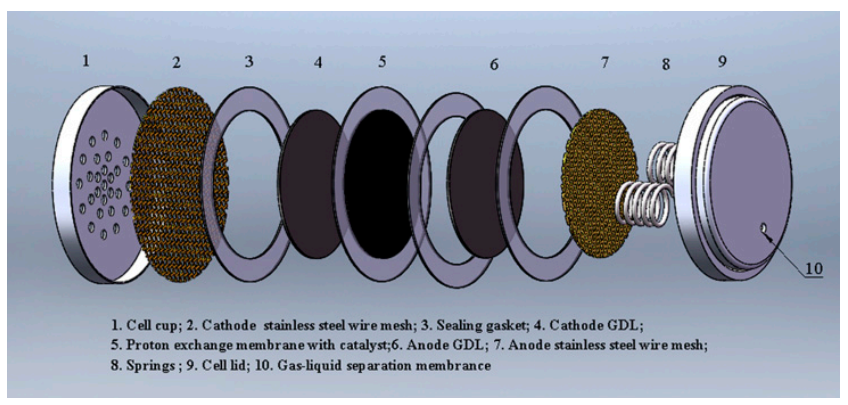

Figure 2. The layout of the $3 D G+S B-\mu D M F C$.

Finally, the B- $\mu$ DMFCs were assembled as four structures: three-dimensional graphene-springs $(3 D G+S)$, carbon paper-springs $(C P+S)$, 3D graphene-foam nickel (3DG + FN), and carbon paper-foam nickel $(\mathrm{CP}+\mathrm{FN})$. It was reported that the optimal packaging pressure of the DMFC was $0.5 \mathrm{MPa}[14,15]$. Considering the plastic deformation of the components, the pressure of our experiments was $1 \mathrm{MPa}$. Figure 3 shows the packaged 3DG $+\mathrm{S}$ B- $\mu$ DMFC. Table 1 shows the physical properties of four B- $\mu$ DMFCs.

A methanol reservoir with the depth of $2.5 \mathrm{~mm}$ was supported by springs in the lid of the cell with springs. The springs for providing and maintaining the compression pressure on the cell were made of 304 stainless steel with good elasticity and low internal resistance. Foamed nickel was also used to replace the springs. A gas-liquid separation membrane was set in the hole in the lid to facilitate of carbon dioxide removal and methanol injection.
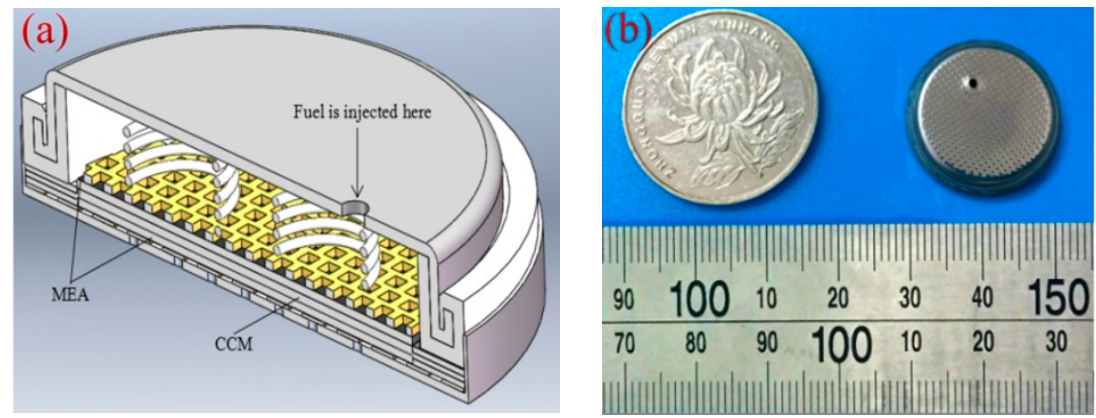

Figure 3. (a) Cross-sectional view of the 3DG $+\mathrm{S} B-\mu \mathrm{DMFC}$; (b) the packaged B- $\mu \mathrm{DMFC}$.

Table 1. Physical properties of the fourbutton-type micro direct methanol fuel cells(B- $\mu$ DMFCs). 3DG, three-dimensional graphene; S, springs; FN, foam nickel; $\mathrm{CP}$, carbon paper; GDL, gas diffusion layer; CC, current collector.

\begin{tabular}{cccccc}
\hline Cell Type & GDL & CC & $\begin{array}{c}\text { Thickness or } \\
\text { Specificationof CC }(\mathbf{m m})\end{array}$ & $\begin{array}{c}\text { Porosity of } \\
\text { GDL }\end{array}$ & $\begin{array}{c}\text { Thickness of } \\
\text { GDL (mm) }\end{array}$ \\
\hline 3DG + S & 3DG & Spring & $0.5 \times 4 \times 5$ & 0.9 & 0.5 \\
3DG + FN & 3DG & FN & 4 & 0.9 & 0.5 \\
CP + S & CP & Spring & $0.5 \times 4 \times 5$ & 0.78 & 0.28 \\
CP + FN & CP & FN & 4 & 0.78 & 0.28 \\
\hline
\end{tabular}

\section{Results and Discussion}

\subsection{Physical Characterization of GDL}

Figure $4 \mathrm{a}$ is a low-magnification scanning electron microscope (SEM) image of 3DG to show the 3DG interconnected network structure in order to provide a large specific surface area and high porosity. 
This structure provides a multi-channel pathway for methanol diffusion and $\mathrm{CO}_{2}$ removal. 3DG is also an excellent current collector owing to its high conductivity. Figure $4 \mathrm{~b}$ is a high-magnification SEM image of 3DG to suggest that graphene was uniformly coated on a FN substrate. The graphene film was continuously grown based on chemical vapor deposition(CVD) [13]. In addition, because of the difference in thermal expansion between the FN and the grown graphene film, irregular wrinkles of the graphene surface can be seen in Figure $4 b$. Figure $4 c, d$ are SEM images of carbon paper and micro-porous layers, respectively. As can be seen from the figure, the Teflon is uniformly covered on carbon fibers, so the water generated in the cell can be eliminated timely. The dense structure of the carbon fiber cross-section is beneficial for the improvement of electrical conductivity, but may cause a lower porosity for being not conducive to the transmission of liquid and gas.

The 3DG has a big deformation after B- $\mu$ DMFCs' assembly. The thickness of 3DG adjusted to $165 \mu \mathrm{m}$ from $495 \mu \mathrm{m}$ under the pressure of $1 \mathrm{MPa}$ and, consequently, the porosity changed from the initial $90 \%$ to $70 \%$, as shown in Figures 4 and 5 .

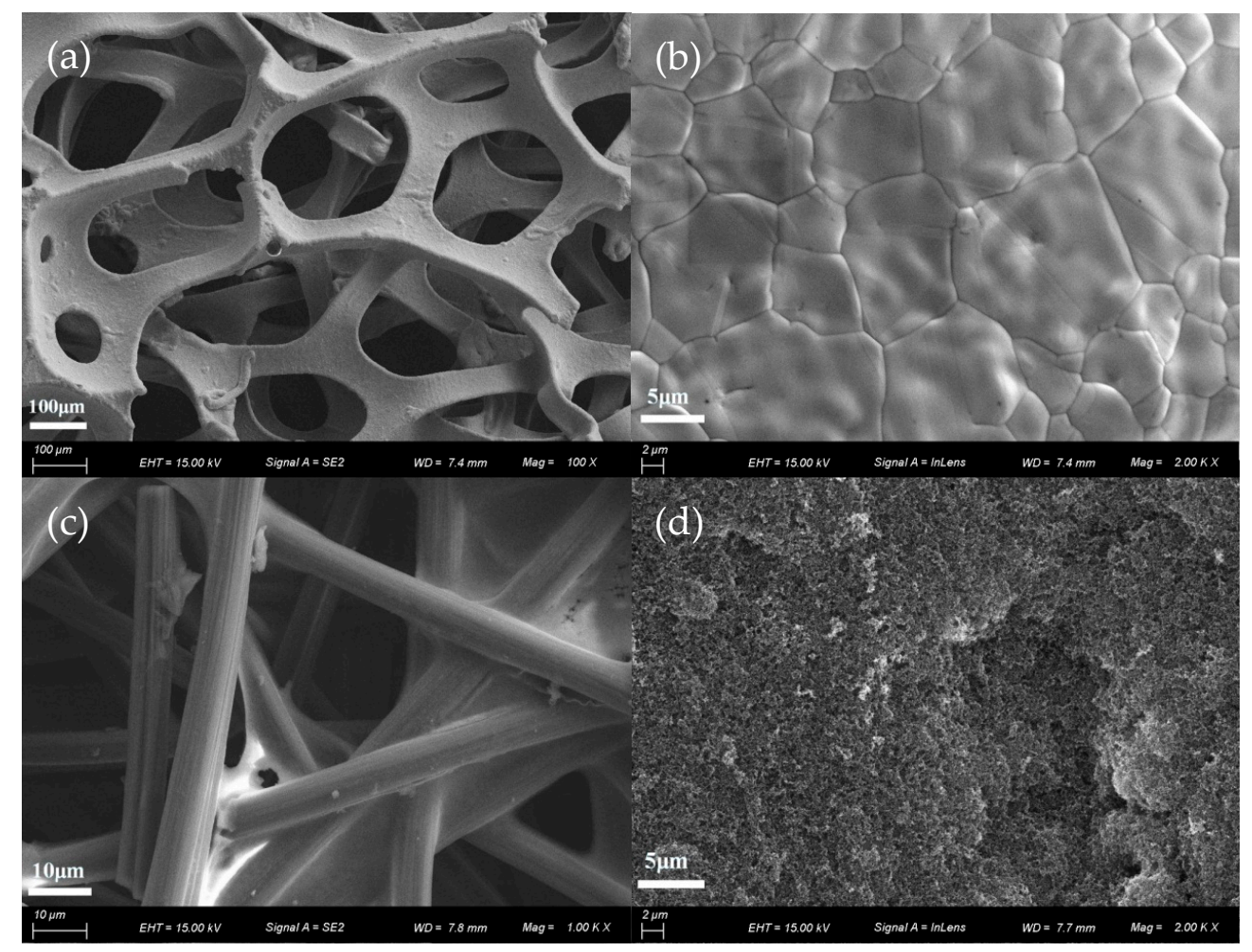

Figure 4. (a,b) Scanning electron microscope (SEM) image of 3DG; (c) anode of CP; (d) microporous layer of $\mathrm{CP}$.

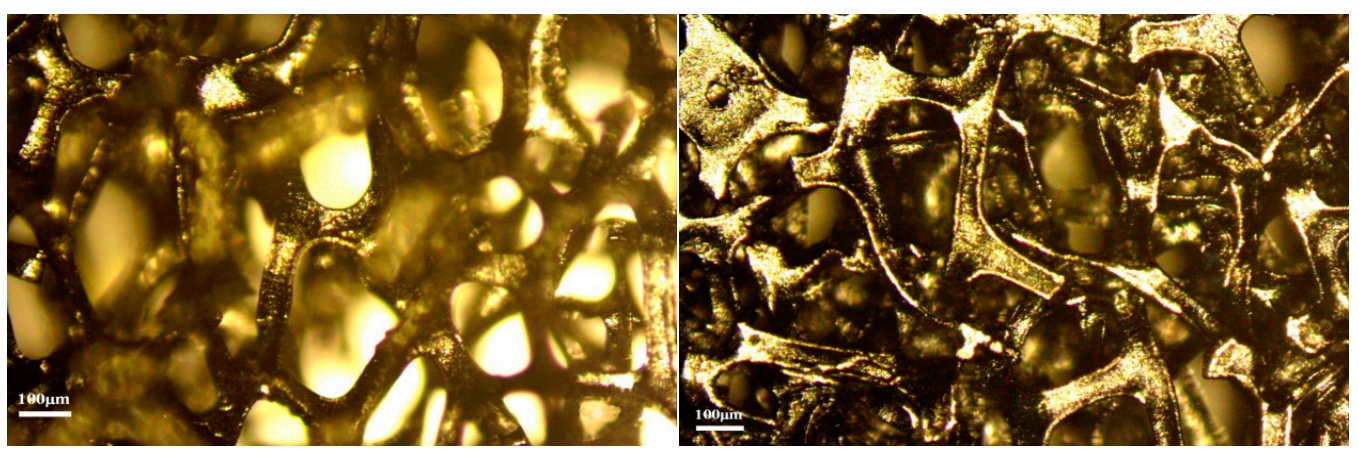

(a)

(b)

Figure 5. Cont. 


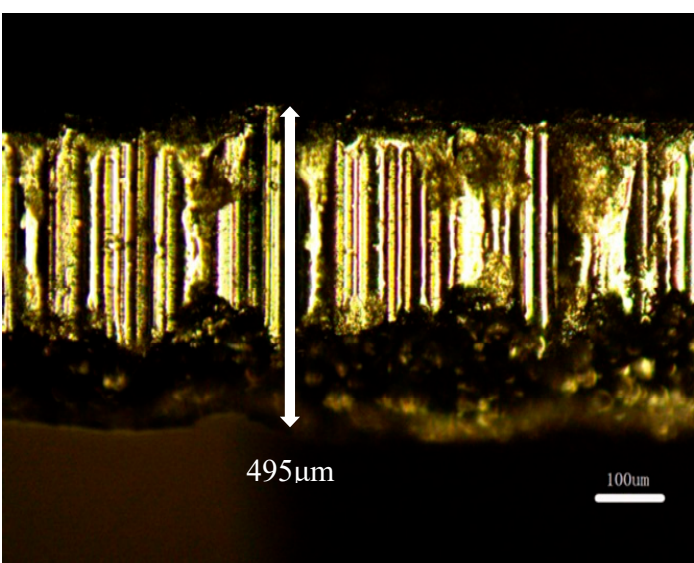

(c)

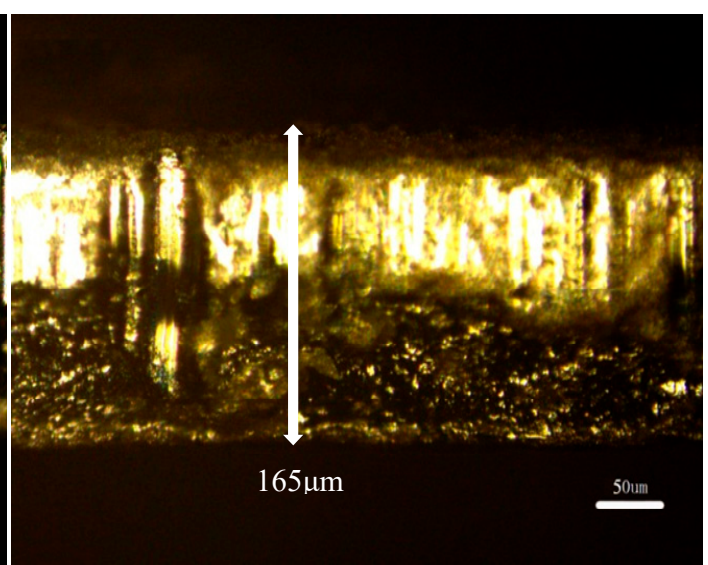

(d)

Figure 5. The view of 3DG: (a) top view before assembly; (b) top view after assembly; (c) cross-sectional view before assembly; (d) cross-sectional view after assembly.

\subsection{Cell Performance}

The B- $\mu$ DMFCs were packaged in a packaging machine for lithium-ion button battery. Before assembly, the cells were tested in a press machine under a constant pressure of $1 \mathrm{MPa}$. Both of the tests of the B- $\mu \mathrm{DMFC}$ before and after packaging were carried out at room temperature and in passive mode. The methanol concentration used in this experiment was $1 \mathrm{~mol} \mathrm{~L}^{-1}$. As shown in Figure $6 \mathrm{a}$, the peak powers of all four cells exceed $10 \mathrm{~mW}$. The peak power of the $\mathrm{CP}+\mathrm{S}$ button cell is $12 \mathrm{~mW}$, which is the lowest of the four cells. The 3DG + FN cell has the highest peak power of $16.5 \mathrm{~mW}$, which means that the cell discharge current can reach $82 \mathrm{~mA}$ when the voltage is rated at $0.2 \mathrm{~V}$. Figure $6 \mathrm{~b}$ shows the Nyquist curve of various structural button fuel cells before packaging. The 3DG + FN button fuel cells have a minimum ohm resistance of $0.4 \Omega$ and the $\mathrm{CP}+\mathrm{S}$ button fuel cells have a maximum ohm resistance of $0.8 \Omega$.

After packaging, the output performances of all button cells decreased because of the excessive pressure and elastic recovery of the shell of the cell after removing the pressure from the packaging machine. This phenomenon was also illustrated in our previous work because of the plastic deformation of the GDL [14]. The peak power of the 3DG + S structural cell changed from $14.5 \mathrm{~mW}$ to $14.2 \mathrm{~mW}$, which was the smallest change of the output power. The ohmic internal resistance changed from $0.46 \Omega$ to $0.48 \Omega$ and the maximum current density of the $3 D G+S$ structural B- $\mu$ DMFC reached $34 \mathrm{~mA} \mathrm{~cm}{ }^{-2}$. The performances of the cells with the other three structures became worse. The performance of the button cell dropped sharply, especially when the foamed nickel (FN) was used as the support structure. The peak power of the 3DG + FN structural fuel cell was $10.75 \mathrm{~mW}$, and the ohmic internal resistance reached $0.89 \Omega$. The performance of the $\mathrm{CP}+\mathrm{FN}$ cell was the worst. The peak power was only $7.5 \mathrm{~mW}$ and the ohm internal resistance was $1.16 \Omega$. This is because the FN cannot store elastic restoring force and has poor contact with the neighbor components, which consequently leads to a large internal resistance of the cell. It can be seen from Figure 5 that the cell performance of 3DG as a GDL for $\mathrm{B}-\mu \mathrm{DMFC}$ is much better than $\mathrm{CP}$, whether the support current collecting structure is springs or FN. Table 2 shows that the B- $\mu$ DMFC has higher power density than some other type DMFCs, especially for power density per unit volume.

Table 2. Comparison of B- $\mu$ DMFC and other two $\mu$ DMFC performance parameters.

\begin{tabular}{ccccc}
\hline Type & Area of $\mu$ DMFC & $\begin{array}{c}\text { Maximum Current } \\
\text { Density }\end{array}$ & $\begin{array}{c}\text { Maximum Power } \\
\text { Density }\end{array}$ & $\begin{array}{c}\text { Power Density per } \\
\text { Unit Volume }\end{array}$ \\
\hline$\mu$ DMFC packaged by bolts [16] & $4.84 \mathrm{~cm}^{2}$ & $30 \mathrm{~mA} \mathrm{~cm}^{-2}$ & $2.35 \mathrm{~mW} \mathrm{~cm}^{-2}$ & $2.94 \mathrm{~mW} \mathrm{~cm}^{-3}$ \\
DMFC packaged by bolts [17] & $72.25 \mathrm{~cm}^{2}$ & $40 \mathrm{~mA} \mathrm{~cm}^{-2}$ & $19.7 \mathrm{~mW} \mathrm{~cm}^{-2}$ & $5.57 \mathrm{~mW} \mathrm{~cm}^{-3}$ \\
B- $\mu$ DMFC & $2.96 \mathrm{~cm}^{2}$ & $34 \mathrm{~mA} \mathrm{~cm}^{-2}$ & $4.78 \mathrm{~mW} \mathrm{~cm}^{-2}$ & $11.85 \mathrm{~mW} \mathrm{~cm}^{-3}$ \\
\hline
\end{tabular}




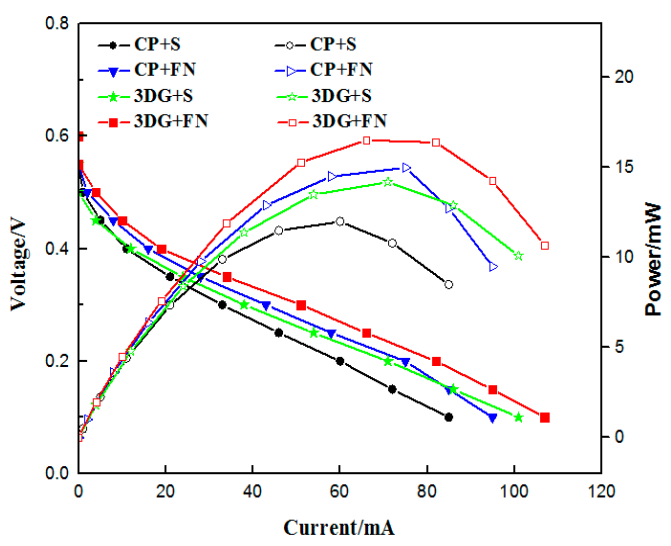

(a)

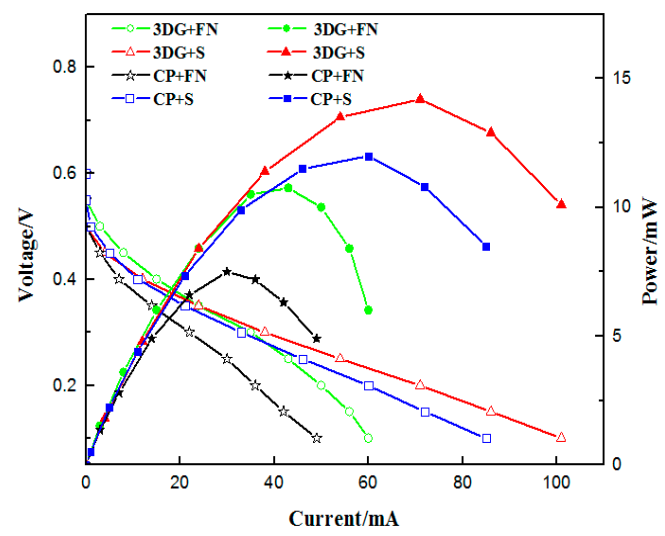

(c)

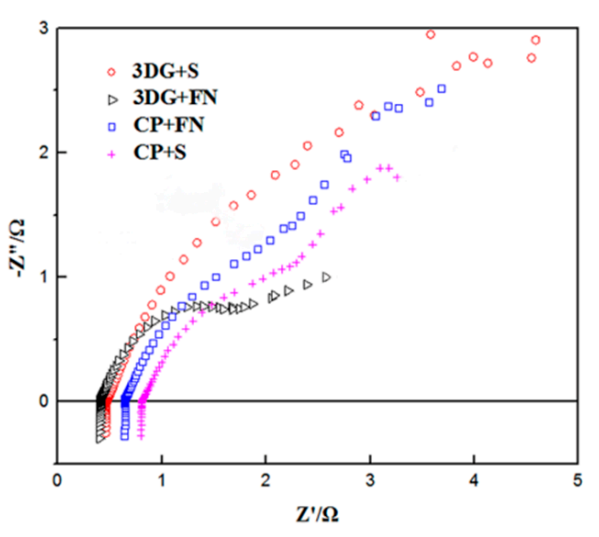

(b)

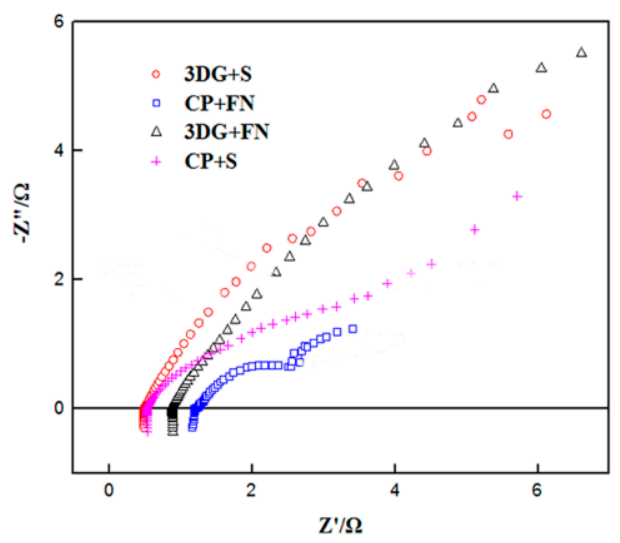

(d)

Figure 6. The polarization curve of various B- $\mu$ DMFCs before packaging (a) and after packaging (c), and the Nyquist curve of various B- $\mu$ DMFCs before packaging (b) and after packaging (d).

\subsection{Equivalent Circuit Fitting}

Considering the complex reaction processes of substances (methanol, oxygen, and water), mass transport and diffusion, and electron transfer during the operation of B- $\mu$ DMFC, the $\mu$ DMFC full cell equivalent circuit (Randles circuit) model [18] was applied to understand the measured cell alternating current(AC) impedance. The measured Bode and Nyquist curves by electrochemical impedance spectroscopy(EIS) technology were fitted using the equivalent circuit model. As shown in Figure $7, R_{\mathrm{m}}$ is the ohmic resistance of the cell, $R_{\mathrm{ct}}$ is the charge transferresistance, $R_{\mathrm{mt}}$ is the mass transfer resistance, $L$ is the pseudo-inductanceinduced by the outside circuits and test equipments, $Q_{1}$ and $Q_{2}$ express the charge and discharge process of the doublelayer capacity of the anode and cathode, and resistance of $R_{\mathrm{CO}}$ and lowfrequency impedance of $L_{\mathrm{CO}}$ express the relaxation process of the $\mathrm{CO}$ product in the anode electrode.

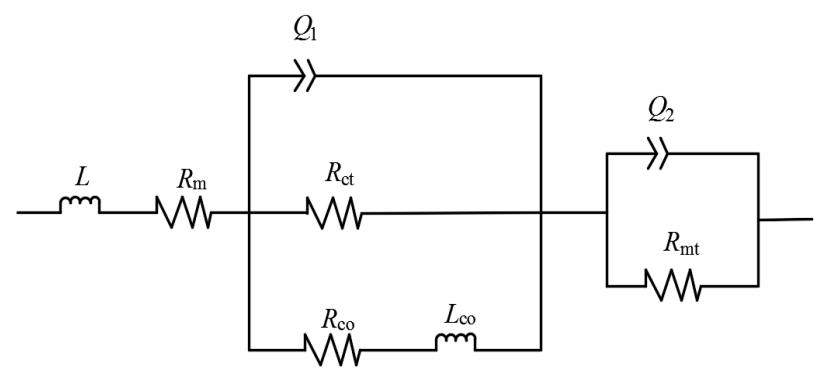

Figure 7. Equivalent circuit (Randles circuit). 
As shown in Table 3, the $R_{\mathrm{m}}$ of the 3DG $+\mathrm{S}$ structural fuel cell is the smallest and the mass transfer resistance is the second-lowest. This is because that the porosity of the 3DG $(70 \%)$ is higher than CP (53\%) after assembly, and because FN has plastic deformation than springs. The difference in contact resistance (a part of $R_{\mathrm{m}}$ ) after assembly may also be the cause of the difference in $R_{\mathrm{m}}$ between spring and FN. Therefore, the methanol can distribute more evenly in the catalytic layer and $\mathrm{CO}_{2}$ can release from the cell anode in time in the B- $\mu \mathrm{DMFC}$ of $3 \mathrm{DG}+\mathrm{S}$. The $R_{\mathrm{m}}$ of the spring-structured cell is smaller than the foamed nickel-structured cell. This is because the spring has good elasticity and the components can be in close contact after being pressed, and the FN has poor elasticity and cannot be recovered after being compressed.

Table 3. Fitted parameters of the Nyquist plots.

\begin{tabular}{cccccc}
\hline Type of $\mu \mathrm{DMFC}$ & $\boldsymbol{R}_{\mathbf{m}}$ & $\boldsymbol{R}_{\mathrm{ct}}$ & $\boldsymbol{R}_{\text {co }}$ & $\boldsymbol{R}_{\mathrm{mt}}$ & Maximum Power Density \\
\hline 3DG + S & $0.45 \Omega$ & $1.82 \Omega$ & $3.52 \Omega$ & $3.6 \Omega$ & $4.78 \mathrm{~mW} \mathrm{~cm}^{-2}$ \\
CP + S & $0.54 \Omega$ & $3.80 \Omega$ & $0.61 \Omega$ & $6.2 \Omega$ & $4.20 \mathrm{~mW} \mathrm{~cm}^{-2}$ \\
CP + FN & $1.15 \Omega$ & $0.67 \Omega$ & $0.27 \Omega$ & $2.01 \Omega$ & $2.53 \mathrm{~mW} \mathrm{~cm}^{-2}$ \\
3DG + FN & $0.86 \Omega$ & $0.15 \Omega$ & $0.38 \Omega$ & $11.6 \Omega$ & $3.62 \mathrm{~mW} \mathrm{~cm}^{-2}$ \\
\hline
\end{tabular}

\section{Anode Methanol Diffusion Model}

\subsection{Deformation Analysis}

The support current collector (FN) and the gas diffusion layer (CP and 3DG) in the cell are porous materials and will be greatly deformed under compression pressure. Large deformation often causes lower porosity of porous materials, which has a great influence on the cell performance. The support current collector FN used herein has a thickness of $4 \mathrm{~mm}$ and the thickness of 3DG is $0.5 \mathrm{~mm}$. The geometric model (shown in Figure 8) consists of the cell lid, anode support current collector, and anode gas diffusion layer (3DG). A uniform pressure of $1 \mathrm{MPa}$ is applied to the cell lid, and the bottom of the GDL is fixed.

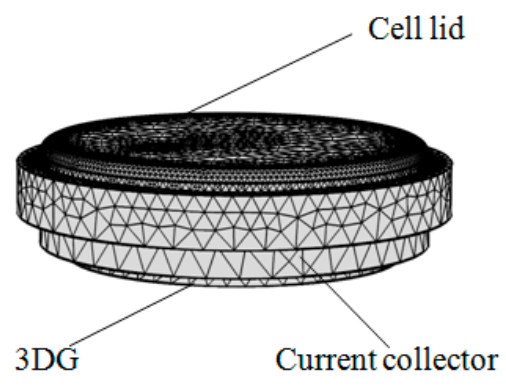

(a)

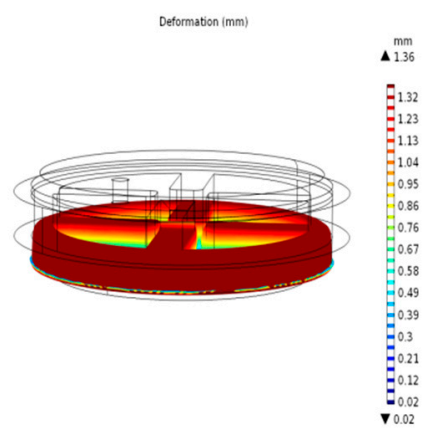

(b)

Figure 8. (a) The calculation model; (b) the deformation of support current collector (FN).

In order to verify the accuracy of the simulation, compression experiments of FN and 3DG were also performed. After applying a pressure of $1 \mathrm{MPa}$ to the $\mathrm{FN}$, the total thickness deformation was $1.52 \mathrm{~mm}$, which was close to the simulated results of $1.39 \mathrm{~mm}$. For 3DG, the thickness of 3DG became $0.16 \mathrm{~mm}$ under the pressure of $1 \mathrm{MPa}$. The void ratio of FN and 3DG after compression deformation can be estimated by the following formula.

$$
\varepsilon=1-\frac{d_{0}}{d}\left(1-\varepsilon_{0}\right)
$$

where $\varepsilon$ is the current porosity of the material, $\varepsilon_{0}$ is the initial porosity before compression (3DG is about $90 \%, \mathrm{FN}$ is about $75 \%$ ), $d$ is the current thickness, and $d_{0}$ is the initial thickness (3DG is $0.5 \mathrm{~mm}$, 
$\mathrm{FN}$ is $4 \mathrm{~mm}$ ). After being applied by $1 \mathrm{MPa}$ pressure, the porosity of the $\mathrm{FN}$ changed to $59 \%$ and the porosity of the 3DG changed from the initial $90 \%$ to $70 \%$. If non-uniform compression of the diffusion layer is taken into account, the actual local porosity of the diffusion layer (3DG) under the current collector rib is even lower.

\subsection{Methanol Concentration Diffusion Model}

In order to better understand the flow distribution of methanol in the anode of the cell, a three-dimensional steady-state mathematical model was developed. In the model, the main focus is on the distribution of methanol concentration in the anode support current collector (FN) and gas diffusion layer (3DG). To simplify the model, several assumptions for the purpose of simplifications are introduced: (1) the B- $\mu \mathrm{DMFC}$ is in steady-state operation; (2) the formation of $\mathrm{CO}_{2}$ on the anode side of the B- $\mu$ DMFC does not affect the methanol diffusion process in the diffusion layer; (3) the support current collector (FN) and gas diffusion layer (3DG) are continuous porous media; and (4) the porosity is uniform in every component.

As there was no electrochemical reaction in the anode diffusion layer, the convection-diffusion equation was used to characterize the methanol concentration distribution in the support current collector (FN) and GDL (3DG).

$$
\nabla \cdot\left(-D_{i} \nabla C_{i}+u C_{i}\right)=R
$$

where $C$ is the methanol concentration, $R$ is the rate of methanol consumption at the interface between the diffusion layer and the catalytic layer, and $D$ is the effective diffusion coefficient of methanol in the diffusion layer. Because of the large mass transfer resistance of the methanol in the anode diffusion layer, the effective coefficient of the aqueous methanol solution was corrected by the Bruggeman model as the following formula:

$$
D=D_{\mathrm{M}} \cdot \varepsilon^{1.5}
$$

where $\varepsilon$ is the diffusion layer porosity and $D_{\mathrm{M}}$ is the diffusion coefficient of methanol in water. The calculation model is shown in Figure 8. The boundary conditions were set as follows: $C=C_{0}$ in methanol inlet, where $C_{0}$ is the fuel concentration in the methanol chamber; $R=-M_{\mathrm{MeOH}}$ on the contact surface of GDL with the catalytic layer, where $M_{\mathrm{MeOH}}$ is the methanol consumption flux as the following formula:

$$
M_{\mathrm{MeOH}}=\frac{I}{6 F}+M_{\mathrm{MeOH}, \mathrm{cross}} .
$$

The first term at the right end of the formula is the methanol flux consumed by the current $I$, the second term is the methanol permeate flux, and $F$ is the Faraday constant.

The small contact area between the spring and the GDL can be ignored. A quarter of the geometric model was chosen to calculate (shown in Figure 9) and the parameters used in the computation are shown in Table 4. As shown in Figure 10a,b, even though the porosity of the GDL (3DG) of the 3DG $+S$ structural cell was reduced after applying clamp force, the methanol diffusion was relatively uniform in the GDL. When the internal fuel concentration was $1 \mathrm{M}$, the lowest methanol concentration at the interface between the 3DG and the catalytic layer was $0.92 \mathrm{M}$. By comparison, the lowest methanol concentration of the 3DG + FN structural cell was about $0.8 \mathrm{M}$, as shown in Figure $9 \mathrm{c}, \mathrm{d}$. This is because the porosity of FN changed from 0.75 to 0.59 after being pressed. Moreover, the methanol concentration under the FN rib was lower than that in the channel. Owing to the large contact area between FN and 3DG and the lower porosity of FN, the consumption of methanol between the 3DG and the catalytic layer made the methanol distribution uneven. This leads to a large mass transfer resistance $R_{\mathrm{mt}}(11.6 \Omega$, in Table 2) and poor cell performance. 


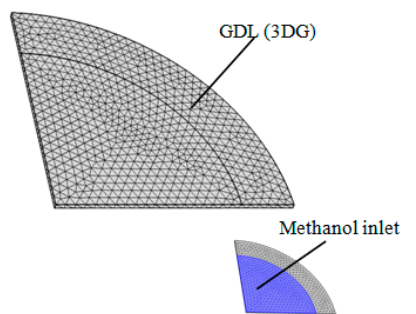

(a)

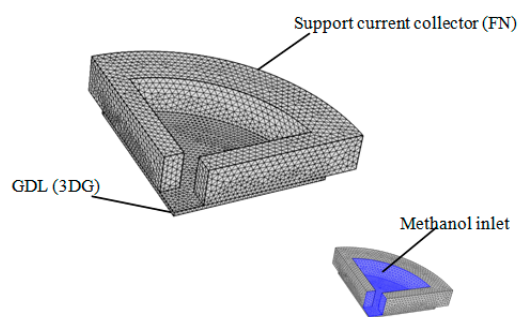

(b)

Figure 9. (a) The methanol concentration diffusion model of the 3DG + S cell; (b) three-dimensional methanol concentration diffusion model of the FN + 3DG cell.

Table 4. Main geometric parameters and working parameters of the B- $\mu$ DMFC model.

\begin{tabular}{ccc}
\hline Parameters & Units & Values \\
\hline Operating temperature T & $\mathrm{K}$ & 300 \\
Thickness of FN & $\mathrm{mm}$ & 2.4 \\
Thickness of 3DG & $\mathrm{mm}$ & 0.16 \\
Porosity of FN & - & 0.59 \\
Porosity of 3DG & - & 0.7 \\
Diffusion coefficient of methanol in water & $\mathrm{m}^{2} \mathrm{~s}^{-1}$ & $10^{-5.4163-999.778 / \mathrm{T}}$ \\
Methanol penetration rate & $\mathrm{mol} \mathrm{cm}^{-2} \mathrm{~s}^{-1}$ & $2 \times 10^{-7}$ \\
Discharge current $I$ & $\mathrm{~mA} \mathrm{~cm}^{-2}$ & 34.12 \\
Methanol consumption flux & $\mathrm{mol} \mathrm{cm}^{-2} \mathrm{~s}^{-1}$ & $2.6045 \times 10^{-7}$ \\
Methanol inlet concentration & $\mathrm{mol} \mathrm{L}^{-1}$ & 1 \\
$F$ & $\mathrm{C} \mathrm{mol}^{-1}$ & 96,485 \\
\hline
\end{tabular}

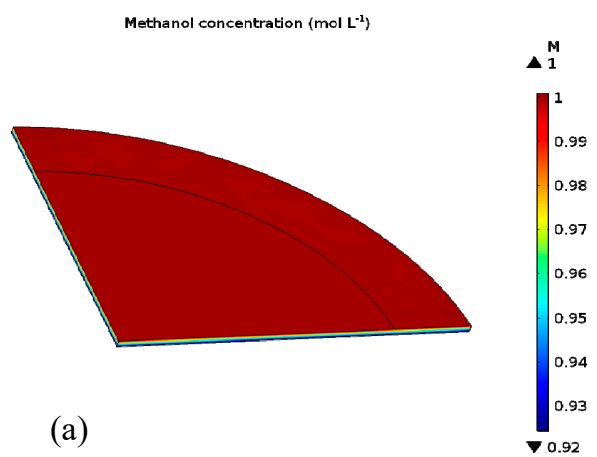

Methanol concentratlon ( $\mathrm{mol} \mathrm{L}^{-1}$ )

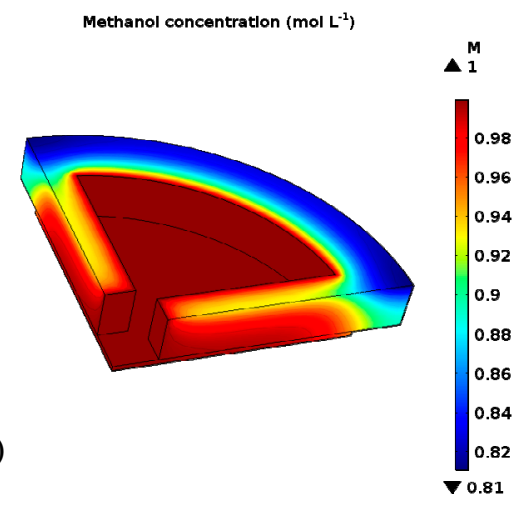

(c)

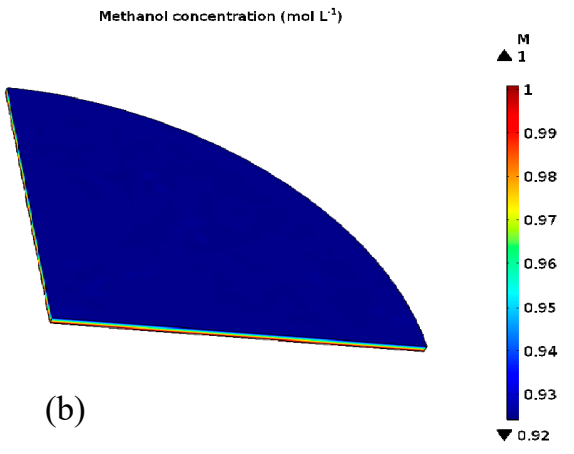

Methanol concentration ( $\mathrm{mol} \mathrm{L}^{-1}$

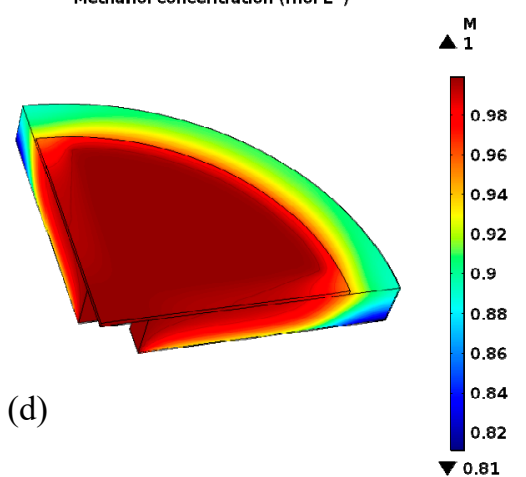

Figure 10. (a) Front view of methanol concentration distributions in the gas diffusion layer (GDL) of the $3 D G+S$ structural cell; (b) back view of methanol concentration distributions in GDL of the 3DG $+S$ structural cell; (c) front view of methanol concentration distributions in the 3DG + FN structural cell; (d) back view of methanol concentration distributions in the 3DG + FN structural cell. 


\section{Conclusions}

A new button-type micro direct methanol fuel cell is designed and manufactured and the performance of the cell is compared with the traditional DMFC. It is found that the performance of the B- $\mu$ DMFC with 3DG as a GDL is better than that with CP. The performance of the cell with spring is better than that with foamed nickel. Equivalent circuit was applied to fit the mass resistance and ohmic resistance of the cell. The methanol concentration diffusion was also simulated to explain the results. The results indicate that the B- $\mu$ DMFC cell with three dimension and springs had the best performance, because it had relative low ohmic resistance and mass transfer resistance. The volumetric specific power density of the packaged B- $\mu$ DMFC with $3 D G+S$ was $11.85 \mathrm{~mW} \mathrm{~cm}{ }^{-3}\left(34 \mathrm{~mA} \mathrm{~cm}^{-2}\right)$, which is four times higher than that of the air-breathing $\mu$ DMFC [15], and is two times higher than that of the passive DMFC [16].

Author Contributions: Investigation, Y.Z. and L.G.; Project administration, Y.Z.; Writing—original draft, Y.Z.; Writing-review \& editing, J.L.

Funding: This research is supported by National Natural Science Foundation of China (No. 51405342).

Conflicts of Interest: The authors declare no conflict of interest.

\section{References}

1. Mallick, R.K.; Thombre, S.B. Performance of passive DMFC with expanded metal mesh current collectors. Electrochim. Acta 2005, 7, 427-430. [CrossRef]

2. Kamarudin, S.K.; Daud, W.R.W.; Ho, S.L.; Hasran, U.A. Overview on the challenges and developments of micro-direct methanol fuel cells (DMFC). J. Power Sources 2007, 163, 743-754. [CrossRef]

3. Lian, K.Y.; Yang, C.M. Sensor-less adaptive fuel concentration control for direct methanol fuel cells under varying load. J. Power Sources 2013, 231, 239-245. [CrossRef]

4. Taymaz, F.A.; Benli, M. Application of response surface methodology to optimize and investigate the effects of operating conditions on the performance of DMFC. Energy 2011, 36, 1155-1160. [CrossRef]

5. Sudaroli, B.M.; Kolaran, A.K. Experimental study on the effect of membrane thickness and PTFE (polytetrafluoroethylene) loading on methanol crossover in direct methanol fuel cell. Energy 2016, 98, 204-214. [CrossRef]

6. Li, X.; Faghri, A. Local entropy generation analysis on passive high-concentration DMFCs (direct methanol fuel cell) with different cell structures. Energy 2011, 36, 403-414. [CrossRef]

7. Young, H.S.; Hyung, J.K.; Woong, K.J.; Byeong, H.K. Development of active breathing micro PEM fuel cell. Int. J. Precis. Eng. Manuf. 2014, 1, 101-106.

8. Takahiro, S.M.; Toshiyuki, M. Design and fabrication of pumpless small direct methanol fuel cells for portable applications. J. Power Sources 2004, 137, 277-283.

9. Min, K.B.; Tanaka, S.J.; Esashi, M.S. Silicon-based micro-polymer electrolyte fuel cells. In Proceedings of the The Sixteenth Annual International Conference on Micro Electro Mechanical Systems, Kyoto, Japan, 23 January 2003; pp. 379-382.

10. Yeom, J.; Mozsgai, G.Z.; Flachsbart, B.R. Microfabrication and characterization of a silicon-based millimeter scale, PEM fuel cell operating with hydrogen, methanol, or formic acid. Sens. Actuator B Chem. 2005, 107, 882-891. [CrossRef]

11. Guo, Z.; Faghri, A. Development of Planar Air Breathing Direct Methanol Fuel Cell Stacks. J. Power Sources 2006, 160, 1183-1194. [CrossRef]

12. Stamm, J.; Varzi, A.; Latz, A. Modeling nucleation and growth of zinc oxide during discharge of primary zinc-air batteries. J. Power Sources 2017, 360, 136-149. [CrossRef]

13. Cheng, C.-K.; Yeh, T.-K.; Tsai, M.-C.; Chou, H.-Y.; Wu, H.-C.; Hsieh, C.-K. The hybrid nanostructure of vertically aligned cobalt sulfide nanoneedles on three-dimensional graph decorated nickel foam for high performance methanol oxidation. Surf. Coat. Technol. 2017, 320, 536-541.

14. Zhu, Y.L.; Liu, C.; Liang, J.S.; Wang, L.D. Investigation of the effects of compression pressure on direct methanol fuel cell. J. Power Sources 2011, 196, 264-269. [CrossRef] 
15. Liu, X.W.; Fang, S.; Ma, Z.Z.; Zhang, Y.F. Structure design and implementation of the passive $\mu$-DMFC. Micromachines 2015, 6, 230-238. [CrossRef]

16. Wang, X.H.; Zhou, Y.A.; Liu, L.T. Capillary-based water removal cathode for an air-breathing micro direct methanol fuel cell. Microsyst. Technol. 2014, 6, 1093-1101. [CrossRef]

17. Munjewar, S.S.; Thombre, S.B. Effect of current collector roughness on performance of passive direct methanol fuel cell. Renew. Energy 2019, 138, 272-283. [CrossRef]

18. Jin, B.D.; Wang, S.B.; Xie, X.F.; Guo, J.W.; Qi, L.; Wang, J.H. AC resistance spectrum of direct methanol fuel cell with low cathode platinum load catalyst. J. Tsinghua Univ. Nat. Sci. Ed. 2008, 12, 2107-2110.

(C) 2019 by the authors. Licensee MDPI, Basel, Switzerland. This article is an open access article distributed under the terms and conditions of the Creative Commons Attribution (CC BY) license (http://creativecommons.org/licenses/by/4.0/). 